\title{
Atitudes Linguísticas: estudo de falas de multheres indígenas na aldeia Guarani Tekoha Añetete
}

\author{
Sonia Cristina Poltronieri MENDONÇA* \\ Aparecida Feola SELLA**
}

\begin{abstract}
* Doutora (2019) em Letras pela Universidade Estadual do Oeste do Paraná - Campus de Cascavel (Unioeste). Docente da Universidade Federal da Integração Latino-Americana (Unila). Contato: soniapoltronieri@yahoo.com.

** Doutora (2000) em Letras pela Universidade Estadual Paulista Júlio de Mesquita Filho. Docente da Universidade Estadual do Oeste do Paraná (Unioeste).Contato: afsella@yahoo.com.br.
\end{abstract}

\begin{abstract}
Resumo:
Apresentam-se, neste artigo, reflexões sobre resultados da pesquisa sobre crenças e atitudes linguísticas realizada com informantes da aldeia Guarani Tekoha Añetete em Diamante d'Oeste, estado do Paraná. A escolha da localidade se deu pela complexidade sociolinguística marcada pelo espaço multiétnico da Tríplice Fronteira e com presença significativa de indígenas Guarani. Para a composição do corpus, foram entrevistadas seis informantes mulheres bilíngues, cuja língua-mãe é o guarani e a segunda língua é o português. Consideram-se as variáveis sexo e faixa etária (de 20 a 35 anos, de 36 a 55 anos e mais de 55 anos). A partir dos princípios teórico-metodológicos da Sociolinguística (LABOV, 2008), bem como de pesquisas focadas em crenças e atitudes linguísticas (MORENO FERNÁNDEZ, 1998; AGUILERA, 2008; CORBARI, 2013), analisa-se o posicionamento das seis informantes com relação às respostas a cinco perguntas do questionário semiestruturado, basicamente voltadas para refletir sobre as manifestações dos componentes cognoscitivo, afetivo e conativo, indicadores da tendência de atitudes linguísticas. Verificou-se que a língua, dentro e fora da aldeia, acena para o prestígio da língua e da cultura Guarani.
\end{abstract}

\section{Palavras-chave:}

Atitudes linguísticas. Guarani. Português brasileiro.

Signum: Estudos da Linguagem, Londrina, v. 22, n. 2, p. 92-113, ago. 2019 


\section{Atitudes Linguísticas: estudo de falas de mulheres indígenas na aldeia Guarani Te ko ha Añe te te ${ }^{1}$}

Sonia Cristina Poltronieri Mendonça; Aparecida Feola Sella

\section{INTRODUÇÃo}

Este artigo apresenta o recorte da variável gênero com relação às atitudes linguísticas de falantes indígenas, bilíngues, da Reserva Indígena Guarani ${ }^{2}$ Tekoha Añetete, no município de Diamante d'Oeste, em região de fronteira do Paraná. Este texto objetiva descrever de que modo se manifestam os componentes de atitudes linguísticas nas falas de seis informantes indígenas bilíngues, considerando quais componentes (cognoscitivo, afetivo e conativo) ocorrem com mais frequência nas respostas das informantes, com relação principalmente aos falares guarani e português brasileiro (doravante $\mathrm{PB}$ ).

A hipótese levantada inicialmente foi a de desprestígio do guarani e valorização do PB. Outra hipótese se refere à existência de diferença na atitude linguística de acordo com os papéis que as mulheres desempenham na família, na comunidade indígena e em outros ambientes internos ou externos da comunidade indígena. Essas hipóteses foram estabelecidas porque o cenário na fronteira do Brasil com o Paraguai e a Argentina favorece tanto manifestações de prestígio linguístico quanto de desprestígio dos falantes diante dos falares locais indígenas Guarani nesta região de fronteira.

A problematização que decorre da opção por esse contexto de contato linguístico gerou duas perguntas: 1) atitudes linguísticas de falantes indígenas bilíngues revelam prestígio ou desprestígio com relação ao próprio falar guarani? 2) de que modo essas atitudes linguísticas se manifestam nos falantes?

Fishman (1999) afirma que o uso da língua e as atitudes linguísticas variam de acordo com os contextos sociais em que ocorrem. Portanto, não se pode pensar na língua desvinculada de seu contexto social, principalmente na sua condição de aspecto constituidor da identidade de determinado grupo étnico.

Consideraram-se pressupostos presentes no Projeto Crenças e Atitudes Linguísticas: Um Estudo da Relação do Português com Linguas em Contato (Projeto CAL), proposto por

\footnotetext{
${ }^{1}$ Este artigo é o recorte da tese de Mendonça (2020) desenvolvida com apoio financeiro de bolsa Capes (2016-2019).

${ }^{2}$ Para este artigo, adotou-se o padrão Guarani, em letra maiúscula, para fazer referência à etnia indígena, e guarani, em letra minúscula, para se referir à língua.
} 
Aguilera (2009), e ainda pesquisas da área da Sociolinguística voltadas para variedades faladas em cenários sociolinguisticamente complexos, isto é, que refletem as particularidades sociais, regionais, culturais e históricas de cada localidade, em especial de contexto indígena.

De acordo com D'Angelis (2015), os povos Guarani e seus diversos subgrupos encontram-se, hoje, distribuídos em territórios por Bolívia, Paraguai, Uruguai, Brasil e Argentina, nas bacias subtropicais dos rios Paraná e Uruguai, na América do Sul. A população indígena no Brasil atualmente soma cerca de 817 mil indígenas, dos quais 502.783 estão distribuídos entre 688 terras indígenas e 315.180 habitam algumas áreas urbanas. Esse número perfaz quase $0,5 \%$ da população brasileira, de acordo com os dados do Censo 2010 do IBGE; e são praticamente 305 etnias diferentes (IBGE, 2010). D’Angelis (2015) explica que a população Guarani no Brasil é de aproximadamente 52 mil indígenas, que vivem em centenas de aldeias espalhadas por mais de 100 municípios brasileiros, localizados em sete estados: Rio Grande do Sul, Santa Catarina, Paraná, São Paulo, Rio de Janeiro, Espírito Santo e Mato Grosso do Sul.

Para Carvalho (2013, p. 91), "em termos linguísticos os Guarani fazem parte do tronco linguístico Tupi, da Família Linguística Tupi-Guarani, da Língua Guarani, apresentando no Brasil os três dialetos: Kaiowá, Nhandeva e Mbyá". A língua guarani abarca um conjunto de povos falantes desse idioma na América do Sul. Melià (2010) define a língua guarani como uma grande metáfora cultural e histórica de um conjunto de povos que, como já dito, se encontram nas bacias subtropicais dos rios Paraná e Uruguai, na América do Sul, espalhados por Bolívia, Paraguai, Uruguai, Brasil e Argentina, e o seu idioma, em suas diversas variedades, é único e falado por todos esses grupos nesses países. Por essa razão, a língua guarani pode ser considerada, segundo Carvalho, como língua histórica do Mercosul.

Embora o guarani seja uma língua falada em cinco países e oficial entre os países do bloco Mercosul, cabe refletir que somente no Paraguai é uma língua oficial desde 2011, ao lado do espanhol. No Brasil, a consolidação do Estado brasileiro como monolíngue em português apagou ou silenciou a realidade linguística de um País com mais de 180 línguas indígenas e outras dezenas de línguas de imigração, além das línguas crioulas, afro-brasileiras e de sinais.

A geração dos dados na localidade indígena Tekoha Añetete demonstrou que há muito a ser explorado, conforme será disposto neste artigo. Em toda a literatura pesquisada - e, portanto, essa reflexão somente tem sentido nesse âmbito -, verificou-se que, na área de conhecimento Letras/Linguística do banco de dissertações e teses da Capes, quadriênio 2015-2018, poucos trabalhos de línguas indígenas e/ ou língua guarani se referem à temática das crenças e atitudes linguísticas. 
A aldeia Tekoha Añetete, nome que significa "Aldeia Verdadeiramente Guarani”, situa-se na Linha Ponte Nova do município de Diamante d'Oeste. O município está situado no extremo Oeste paranaense, a $595 \mathrm{~km}$ da capital do estado, Curitiba. De acordo com o IBGE (2010), o município tem 5.027 habitantes, 2.561 na área urbana e 2.466 na área rural. Segundo o IBGE (2019), a população estimada foi de 5.253 habitantes. Em 21 de dezembro de 1987, a Lei Estadual n. 8.674 criou o município de Diamante d'Oeste, desmembrando-o do município de Matelândia. Vizinho dos municípios São José das Palmeiras, Ramilândia, Missal e Santa Helena, Diamante d'Oeste está situado a 514 metros de altitude e nas seguintes coordenadas geográficas: Latitude $24^{\circ} 56^{\prime} 46^{\prime \prime}$ Sul e Longitude $54^{\circ} 6^{\prime} 13^{\prime \prime}$ Oeste. A Figura 1 ilustra a localização de Diamante d'Oeste no mapa paranaense.

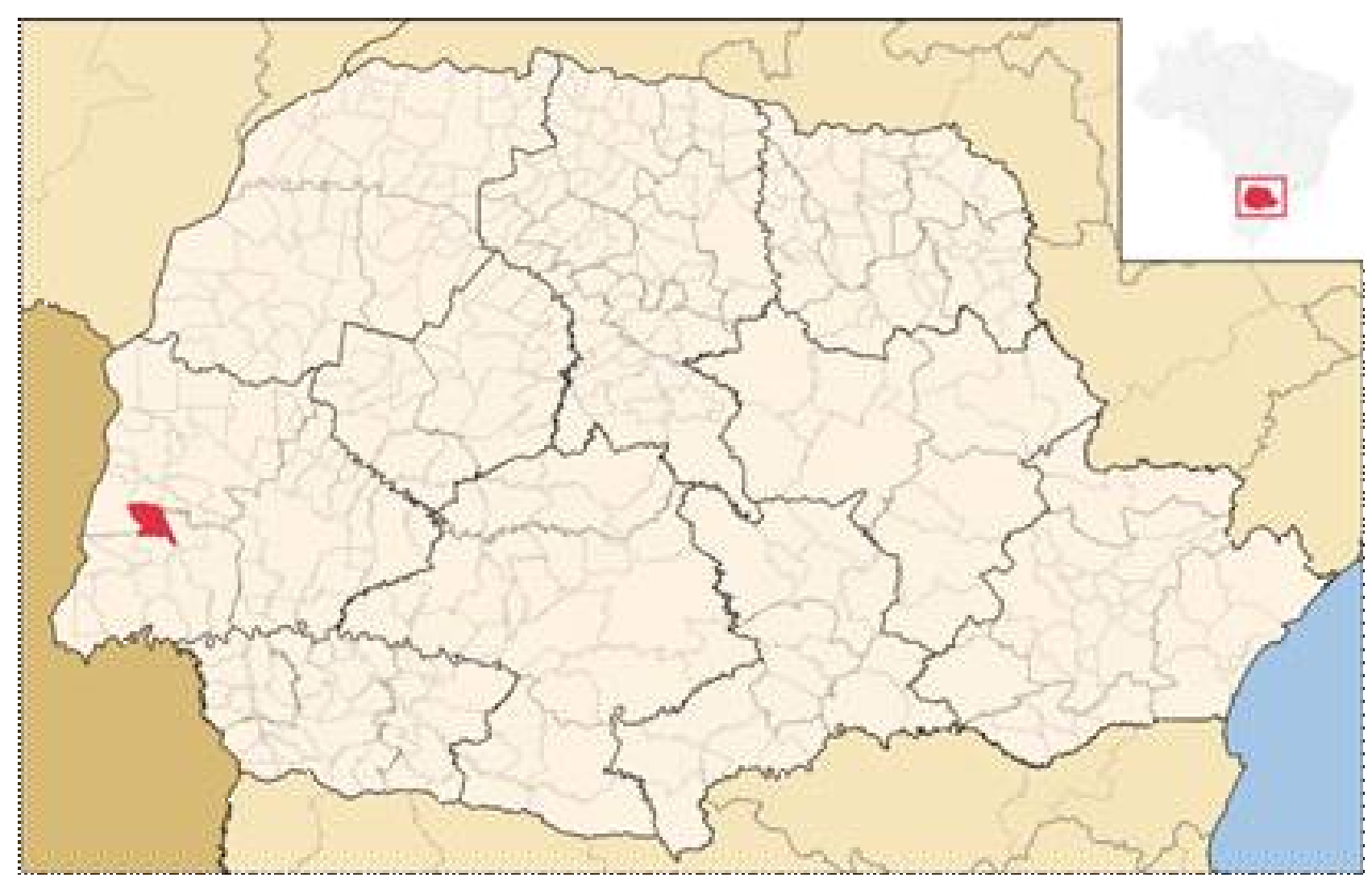

Fonte: Elaborado por Abreu (2006).

Figura 1 - Localização do município de Diamante d’Oeste

A aldeia Tekoha Añetete ocupa um território de 1.744 hectares e está localizada a cerca de 20 quilômetros do centro urbano de Diamante d'Oeste e a aproximadamente 110 quilômetros de Foz do Iguaçu, conforme ilustra a Figura 1. A aldeia é uma reserva 
indígena legal, homologada pelo Decreto s/n 28/7/2000 (FUNAI, 2018) e conquistada pelas famílias que ali se estabeleceram desde 19 de abril de 1997, depois de uma longa mobilização da comunidade indígena atingida com a construção da Usina Hidrelétrica Itaipu Binacional. A formação do Lago de Itaipu, a partir de 1982, resultou no alagamento de grandes porções do território tradicional dos Guarani no extremo Oeste do Paraná, atingindo o Tekoha Guassu(çu) Jacutinga com a dispersão de muitos grupos para outras regiões. Segundo Bortolini (2014), o Tekoha Guassu(cu) Jacutinga compreendia uma área de 1.500 hectares, sendo o último lugar entendido como área indígena no Brasil em que esses Guarani habitaram antes da desterritorialização das famílias atingidas.

De acordo com o cacique da aldeia, o início da aldeia Tekoha Añetete beneficiou cerca de 30 famílias remanescentes do Tekoha Jacutinga, com uma população, em 2019, composta por aproximadamente 420 pessoas, entre adultos e crianças, que vivem basicamente da venda de artesanato e da agricultura de subsistência desenvolvida pelas famílias que vivem na aldeia. O censo demográfico do IBGE (2010) revelou que 286 indígenas são alfabetizados, representando aproximadamente $70 \%$ dos indígenas da aldeia. Essa população pertence ao subgrupo Nhandeva, uma das três divisões dos povos Guarani; falam a língua guarani, com predominância do dialeto Nhandeva, traço de extrema importância na manutenção da cultura étnica. A língua guarani é aprendida pela criança junto à família e a aquisição do $\mathrm{PB}$ como segunda língua ocorre a partir de 4 e 5 anos de idade, quando começam a frequentar o Colégio Estadual Indígena Kuaa Mbo'e, situado na própria aldeia.

Com relação ao tipo de moradia, conforme dados do IBGE (2010), predominam as casas, das quais $87,9 \%$ têm energia elétrica e saneamento básico com água potável, que foram construídas pela Usina Hidrelétrica Itaipu Binacional no início do assentamento das famílias na aldeia. A maioria das casas tem antena parabólica de televisão e uma torre de telefonia celular está instalada na escola.

A população residente no Tekoha Añetete conta com atendimento no posto de saúde da aldeia, de segunda a sexta-feira, que oferece serviços básicos, com um médico, uma enfermeira e um dentista, e dois agentes de saúde Guarani. A unidade de saúde conta, ainda, com dois carros de apoio para transporte de emergência até a unidade médica mais próxima, inclusive aos sábados, domingos e feriados. A aldeia possui, ainda, três casas de reza, campo de futebol e um espaço comunitário para atividades de lazer, cultura e artesanato.

\section{Crenças e Atitudes Linguísticas}

Os princípios teórico-metodológicos da Sociolinguística, de Crenças e Atitudes, da Psicologia Social e dos Estudos da Linguagem são utilizados para fundamentar este estudo, partindo do pressuposto de que a atitude linguística de um indivíduo é o resultado 
da soma de suas crenças, seus conhecimentos, seus afetos e suas tendências a se comportar de forma determinada diante de uma língua ou de uma situação sociolinguística. Os estudos sobre atitudes constituem importante contribuição para a reflexão sobre o ambiente sociolinguístico de uma sociedade, principalmente em contextos de diversidade linguística, como o existente na região do extremo Oeste do Paraná.

Os psicólogos Lambert e Lambert (1966) foram precursores da técnica matched guise (falsos pares) com estudantes de fala francesa e inglesa na cidade canadense de Montreal. O objetivo dos pesquisadores era verificar a qual das línguas era atribuído mais prestígio, como um grupo via o outro a partir de seu idioma e de que maneira as atitudes de um grupo maior influenciavam um grupo menor. De acordo com Aguilera (2008, p. 105 citando Lambert, 1967), o autor preocupava-se em compreender "a manifestação de preferências e convencões sociais acerca do status e prestígio de seus usuários que ele chamou de atitude, observando que os grupos sociais de mais prestígio social' exercem poder nas atitudes linguísticas das comunidades de fala. Embora esse estudo não tenha sido sociolinguístico, a pesquisa constatou atribuição de maior prestígio e mais características positivas aos supostos falantes de inglês. Aguilera e Silva (2014, p. 706) destacam, com base nesse estudo,

que as atitudes dos membros de um grupo menor são afetadas pelos contatos com grupos considerados de posição social mais elevada, pois tais informantes manifestam um sentimento de inferioridade em relação ao seu próprio idioma devido, sobretudo, à coerção que sofrem do grupo maior (idioma inglês).

Essa constatação se confirmou de modo semelhante no estudo sociolinguístico posterior de Labov (2008), ${ }^{3}$ ou seja, a fala do grupo de maior status tem mais prestígio em relação à fala do grupo de classe mais baixa. Labov (p. 21) alertou, em suas pesquisas, que "não se pode entender o desenvolvimento de uma mudança linguística sem levar em conta a vida da comunidade em que ela ocorre", porque as pressões sociais operam continuamente sobre a língua.

Observa-se que há um vínculo entre atitudes e comportamento, ou seja, as atitudes influenciam também o comportamento do falante em relação às línguas, que pode ser afetado também por outros fatores extralinguísticos. As abordagens teóricas sobre atitudes linguísticas têm sido balizadas a partir da definição que estabelecem para atitudes, a saber: a mentalista, de natureza psicológica, e a comportamentalista. Segundo Moreno Fernández (1998), na linha comportamentalista, as atitudes são interpretadas "como uma conduta, como uma reação ou resposta a um estímulo, isto é, a uma língua, a uma

${ }^{3}$ Lembrando que a obra foi originalmente publicada em 1972. Utilizamos, neste artigo, a publicação de 2008. 
situação ou algumas características sociolinguísticas determinadas" ${ }^{4,5}$ (p. 182, tradução nossa). Para a abordagem mentalista, que sustenta as análises de muitos trabalhos sobre atitudes linguísticas, inclusive este, por ser um estado mental tão intangível, não é possível medi-la ou observá-la diretamente, de modo que é necessário recorrer a técnicas indiretas (GÓMES MOLINA, 1996; MORENO FERNÁNDEZ, 1998; BLANCO CANALES, 2004).

Os estudos que dizem respeito a crenças e atitudes linguísticas podem colaborar significativamente para o aclaramento da postura de falantes de diversas regiões geográficas, em relação à sua própria fala e ao falar do outro, ou seja, o entendimento da realidade linguística de uma comunidade, região ou país e que possa explicar o fato de que falantes modificam seu comportamento linguístico de acordo com a identidade do grupo de fala e dos indivíduos com os quais se relacionam. Considera-se, portanto, que a língua tem uma dimensão social e se manifesta na comunicação e na interação entre o indivíduo e a sociedade em que ele atua.

Moreno Fernández (1998) concebe que a atitude linguística é constituída por três elementos, que se situam no mesmo nível: o saber ou crença (componente cognoscitivo), a valoração (componente afetivo) e a conduta (componente conativo). Em relação a esses elementos, a manifestação do falante pode revelar juízos de valor, crenças, intenção de conduta, reação de prestígio ou desprestígio e consciência linguística sobre determinados contextos e circunstâncias. Uma das consequências diretas da consciência linguística é a segurança ou insegurança linguística dos falantes, que Moreno Fernández explica da seguinte forma:

fala-se de segurança linguística quando o que o falante considera correto ou adequado coincide com os usos espontâneos do mesmo falante; a insegurança linguística surge quando tal coincidência diminui ou desaparece. O protótipo de um falante inseguro seria aquele capaz de fazer afirmações como estas: nunca me ocorreria dizer que caí ou nunca direi coisas como iria ou viria ${ }^{6}(1998$, p. 182).

Sobre a língua, o comportamento do falante em relação à própria variedade admite a ocorrência de duas atitudes: a de valorização e a de rejeição, ou seja, a mesma variedade pode ser objeto de atitudes positivas ou negativas, dependendo da valoração que se faz dentro do grupo em que se fala. Segundo Aguilera (2008, p. 106), "qualquer

\footnotetext{
${ }^{4}$ como una conducta, como una reacción o respuesta a un estímulo, esto es, a una lengua, una situación o unas características sociolingüisticas determinadas.

${ }^{5}$ Todas as traduções neste artigo são nossas.

${ }^{6}$ se habla de seguridad lingüistica cuando lo que el hablante considera como correcto o adecuado coincide con los usos espontáneos del mismo hablante; la inseguridad lingüistica surge cuando tal coincidencia disminuye o desaparece. El prototipo de bablante inseguro sería aquel capaz de hacer afirmaciones como éstas: A mi nunca me ocurrivía decir me se ha caido o Yo jamás diré cosas como irié o vendrie.
} 
atitude em relação aos grupos com determinada identidade pode, na realidade, ser uma reação às variedades usadas por esse grupo ou aos indivíduos usuários dessa variedade". Em decorrência dessa condição, as atitudes linguísticas das informantes Guarani em relação às línguas, à escola e ao contato fora da aldeia refletem-se no julgamento e no uso das línguas guarani e PB.

Aguilera coordenou, no período de 2008 a 2012, o Projeto Crencas e Atitudes Linguísticas: Um Estudo da Relação do Português com Linguas em Contato (CAL), com o objetivo de fomentar a integração de grupos de pesquisa voltados para as questões de descrição e análise linguísticas do Português falado no Paraná. O Projeto CAL teve como objetivo produzir um corpus sobre crenças e atitudes linguísticas em oito cidades paranaenses. Dessas cidades, seis estão localizadas na região de fronteira com a Argentina e/ou o Paraguai, sendo elas: Santo Antônio do Sudoeste, Pranchita, Capanema, Foz do Iguaçu, Marechal Cândido Rondon e Guaíra; e duas estão localizadas no interior do estado: Ponta Grossa e Irati. A proposta foi desenvolvida em conjunto com docentes da Unioeste, da UEL, da UEPG e da UEM.

O Projeto CAL revitalizou o interesse pelo estudo sociolinguístico de algumas localidades de contextos multilíngues marcados pelo histórico de imigração e pela proximidade de fronteira com a Argentina. Um dos resultados de pesquisa é a tese de Corbari (2013), intitulada Atitudes Linguísticas: Um Estudo nas Localidades Paranaenses de Irati e Santo Antônio do Sudoeste, em que a pesquisadora investigou as atitudes linguísticas manifestas por falantes de duas localidades paranaenses: Santo Antônio do Sudoeste, situada na região Sudoeste, na fronteira com a Argentina, e Irati, na região Sudeste. Devido às realidades sócio-históricas dos cenários sociolinguísticos complexos das duas localidades, a pesquisa investigou a possibilidade de as línguas em contato gerarem atitudes linguísticas diferenciadas nas duas comunidades. Após análise dos dados, Corbari apontou resultados que indicam atitudes positivas dos informantes em relação às línguas e aos seus falantes em ambas as comunidades. Contudo, uma parcela pequena dos informantes apresentou manifestações de preconceitos fundadas em visões estereotipadas, culturalmente construídas, ou mediadas por questões de identidade.

\section{Procedimentos Metodológicos}

As leituras para a fundamentação teórica contribuíram para a definição dos objetivos, o estabelecimento dos procedimentos metodológicos e a elaboração dos documentos enviados à Fundação Nacional do Índio (Funai), ao Conselho Nacional de Pesquisa e Desenvolvimento Tecnológico (CNPq), ao Comitê de Ética em Pesquisa (CEP) da Unioeste, à Comissão Nacional de Ética em Pesquisa (CONEP), para autorização de acesso à localidade indígena e geração dos dados da pesquisa com os informantes bilíngues da aldeia indígena Tekoha Añetete, de acordo com as Resoluções 
CNS 466/2012, CNS 510/2016 (para ciências humanas) e a Instrução Normativa 001/ PRES/1995 da Fundação Nacional do Índio (Funai).

Adotou-se uma metodologia baseada na teoria mentalista, que permite medir as variáveis da atitude linguística, como a relação entre um estímulo ao falante a partir de uma pergunta e a resposta valorativa desse falante. A concepção mentalista caracteriza a atitude como uma estrutura componencial múltipla, formada pelos elementos afetivo (emoções e sentimentos), cognoscitivo (percepções, crenças e estereótipos presentes no indivíduo) e comportamental ou conativo (tendência a atuar e a reagir de certa maneira com respeito ao objeto). A partir desse pressuposto teórico, utilizado por pesquisadores do Projeto CAL, como Corbari (2013), elaboraram-se as perguntas do questionário de modo que permitissem o estímulo para a manifestação das atitudes linguísticas do falante indígena Guarani bilíngue. As entrevistas com seis informantes mulheres definiram-se a partir do seguinte perfil: a) pessoa que viveu na aldeia Tekoha Jacutinga e reside na aldeia Tekoha Añetete desde a sua fundação, no ano de 1997; b) pessoa que é descendente de família que viveu na aldeia Tekoha Jacutinga, e reside na aldeia Tekoha Añetete desde a sua criação, em 1997.

As informantes bilíngues foram entrevistadas de acordo com o perfil e a variável de faixa etária, de diferentes famílias da localidade Tekoha Añetete, a partir de uma lista de nomes da equipe pedagógica da escola e lideranças da aldeia. $\mathrm{O}$ anonimato das participantes foi mantido tanto na pesquisa documental quanto nos dados gerados pelos questionários e entrevistas, o que é referendado pelas seguintes siglas: M para mulheres; 1 para faixa etária de 21 a 35 anos, 2 para faixa etária de 36 a 55 anos, 3 para faixa etária com mais de 55 anos; e a sequência de 1 a 6 para identificar a informante. Por exemplo, a sigla $1 \mathrm{M} 1$ se refere à informante mulher 1, da faixa etária de 21 a 35 anos.

O instrumento para geração de dados foi elaborado com o objetivo de realizar a análise de acordo com a concepção mentalista. Na elaboração do questionário semiestruturado para a geração dos dados com as informantes, também se considerou o aporte teórico de Lambert e Lambert (1966), de Labov (2008) e de Moreno Fernández $(1998,2012)$, bem como realizou-se uma adaptação no modelo do questionário utilizado pelo Projeto CAL (AGUILERA, 2009) para a realidade sociolinguística e cultural da comunidade de fala investigada. Foram realizadas oito modificações até a versão final do questionário, que contou com 50 perguntas.

As perguntas do questionário foram agrupadas em cinco blocos, com a seguinte apresentação: Bloco 1 - Identificação das línguas de aquisição e de uso do informante; Bloco 2 - Consciência da diversidade e nível de conhecimento das línguas faladas na localidade; Bloco 3 - Percepção sobre o comportamento social e linguístico dos falantes; Bloco 4 - Avaliação das línguas e dos falantes pelo informante; e Bloco 5 - Identificação de tendências à reação. A organização das perguntas em blocos buscou suscitar indices dos componentes cognoscitivo, afetivo e conativo, com o objetivo de que as respostas 
fossem reveladoras das atitudes. $\mathrm{O}$ termo índice atitudinalé utilizado na análise para referência aos três componentes das atitudes, julgados inter-relacionados, e entende-se que as crenças são de natureza cognoscitiva, mas podem desencadear reações emocionais e comportamentais.

\section{Análise dos Dados}

Para este artigo, selecionaram-se as respostas das seis informantes mulheres em relação a uma pergunta de cada bloco:

Pergunta 11: Que língua você fala? (Bloco 1)

Pergunta 22a: Na escola da aldeia, quais são as línguas faladas? (Bloco 2)

Pergunta 22b: Como você se sente(ia) quando precisa(va) usar o português na escola? (Bloco 3)

Pergunta 44: Qual língua é mais feia? (Bloco 4)

Pergunta 47: E se você precisasse trabalhar fora da aldeia, você procuraria um brasileiro, um argentino ou um paraguaio? (Bloco 5)

Nas respostas à pergunta 11, Que língua você fala?, as seis informantes manifestaram o componente cognoscitivo para afirmar que falam guarani. Embora utilizem, durante a entrevista, o PB, as informantes não declaram que falam o PB, o que denota a lealdade linguística à língua materna e identidade étnica, como mostram as respostas:

Pergunta 11: Que língua você fala?

Inf. 1M1

L86NQ: Que língua você fala?

L87INF: Guarani... na verdade boje em dia é tudo ... como é ... é tudo misturado assim... falo guarani, eu aprendi também falar guarani Mbya, eu falo

L89INQ: Por que ... tem diferença?

L90INF: Tem diferença sim a língua guarani pro outros linguas, por exemplo, guarani Kaiowá fala um pouco mais diferente da pessoa que mora aqui

L91INQ: E você fala o Mbya e tem o Nhandeva?

L92INF: Nhandeva também. Nhandeva que se fala mais aqui

L93INQ: É o que fala mais, você fala os dois então?

L94INF: $\operatorname{Sim}$

Inf. 2M1

L31INF: Guarani 
Inf. 3M2

L50INF: Guarani

Inf. 4M2

L74INF: Guarani

Inf. 5M3

L79INF: Só o Guarani memo

Inf. 6M3

L167INF: Guarani

A informante 1M1 aciona o componente cognoscitivo ao recorrer à expressão "tudo ... é tudo misturado assim" e "tem diferença sim a lingua guarani pro outros linguas", o que demonstra que a informante tem consciência das variações linguísticas no modo de falar a língua guarani em três dialetos (Mbya, Nhandeva e Kaiowá). A fronteira favorece as variações linguísticas entre as línguas e a manifestação de fenômenos como o code mixing e o code switching, que têm sido estudados em comunidades bilíngues, para explicar a mistura de línguas e/ou a alternância de códigos na fala de adultos e crianças bilíngues.

O estudo do fenômeno code mixing, no aspecto de competência linguística bilíngue, aponta duas possibilidades de análise pelos estudiosos. De acordo com Von Borstel (2011), uma delas enfoca a relação de mistura de língua com alternância de código na fala de adultos e "a outra centrou-se no processo linguístico de mistura de língua, quando ocorre a aquisição do input linguístico de crianças bilíngues, em relação à diferenciação das duas línguas" (p. 116-117). No que se refere à alternância de código, um fenômeno que ocorre em falantes que vivem em comunidades bilíngues e ou multilíngues, Von Borstel (2011) explica:

Os modelos estudados para interpretação da alternância de código concentram-se, na maioria das vezes, em dois aspectos diferentes: um no plano linguístico de regras gramaticais, denominados de condicionamentos gramaticais, e o outro no plano sociocultural e pragmático, pelo qual se entende a alternância de código como uma estratégia discursiva na interação comunicativa de falantes multilíngues (p. 120).

Destaca-se que, das seis informantes, apenas 1M1 apresenta consciência com relação à variação linguística do próprio guarani. Inclusive, expressa o seu grau de proficiência com relação às variantes. Porém, não menciona $\mathrm{o} P B$, embora esteja respondendo nesta última língua e com alto grau de proficiência e domínio do $\mathrm{PB}$, como é possível identificar no uso do modalizador "na verdade", ou de "por exemplo", para destacar a consciência linguística etc. Logo, 1M1 aciona seu conhecimento com relação ao seu falar bilíngue, o que é indício do componente cognoscitivo. 
A informante 5M3 faz uso de termos como "só" e "memo" (mesmo), que são indicadores de argumentação, o que destaca a presença do componente cognoscitivo.

Constata-se nas respostas das seis informantes, em relação à pergunta 11 , que o componente cognoscitivo se manifesta para revelar a lealdade linguística de valorização da língua materna guarani, que é a língua de identidade étnica do grupo social Guarani, do qual faz parte a aldeia Tekoha Añetete.

Em relação à pergunta 22a, Na escola da aldeia, quais são as linguas faladas?, as seis informantes manifestam o componente cognoscitivo na percepção de que são falados o guarani e o PB. De acordo com as respostas, no espaço da escola, o guarani é a língua de prestígio para fins de comunicação entre os alunos e os professores Guarani da localidade; e o PB é a língua de prestígio para a comunicação entre os alunos/professores Guarani e os professores/funcionários não indígenas do Colégio Estadual Indígena Kuaa Mbo’e. Observem-se as respostas:

Pergunta 22a: $\mathrm{Na}$ escola da aldeia, quais são as línguas faladas?

Inf. 1M1

L322INQ: E na escola da aldeia, quais são as línguas faladas?

L323INF: Guarani ... e como tem professores branco, professora, é claro que elas falam em português pros alunos né ... dai os alunos tem que conversar com eles em português, só que assim sempre em guarani entre eles assim

Inf. 2M1

L210INF: Aqui ensinam quase todas as línguas, menos francês ((risos))

Inf. 3M2

L168INF: É guarani porque todo mundo estuda junto ... tudo guarani ...conversa junto tudo guarani ... só professor que não fala guarani fala portugueis porque não entende

Inf. $4 \mathrm{M} 2$

L218INQ: E na escola aqui da aldeia, quais são as línguas faladas?

L219INF: Lingua?

L220INQ: É

L221INF: Guarani

L222INQ: E tem mais alguma língua além do guarani?

L223INF: Não

L224INQ: Mas quando você vai lá pra aprender, você fala em que língua na escola?

L225INF: Português 
Inf. $5 \mathrm{M} 3$

L165INF: tudo igual, tudo Guarani, alguma fala portuguei, algum tem ingleis ... tudo crianca que tá estuda aprendeno

Inf. 6M3

L571INF: tem pessoa que ensina Guarani ... tem professor que ensina Guarani... e tem professora que ensina brasileiro... e tem mais outro ensina espanbol ... mais não fui ainda no espanbol

Embora na escola sejam faladas as línguas guarani e PB, nota-se que o guarani é a língua mais prestigiada entre os falantes Guarani. Para 1M1, esse processo de comunicação e as diferenças no modo de falar se desenvolvem de acordo com a situação na sala de aula. Inicialmente, 1M1 responde que a língua falada é guarani e em seguida afirma que há professores "branco" e professora que falam em PB. A utilização do termo "branco" demonstra a consciência de que os professores que falam PB são de etnia diferente do Guarani e não são indígenas. Para explicar esse processo de interação verbal na escola, 1M1 manifesta o componente conativo ao destacar a atitude de conduta dos falantes, ou seja, os alunos têm que conversar em PB com os professores e "sempre" em guarani entre os alunos.

Apesar de não nominar as línguas faladas na escola, 2M1 tem a percepção de que, nesse espaço, falam-se quase todas as línguas, menos o francês, o que revela que sua resposta ocorre a partir do contato com as línguas que estudou na escola. Já 3M2 demarca o prestígio do guarani na comunicação entre os alunos e usa os modalizadores "todo" e "tudo" para apontar que somente o professor não fala guarani porque não entende essa língua. A informante 4M2 tem uma reação de dúvida quando pergunta "Língua?" e em seguida responde "guarani”" e que não há outra língua falada na escola além do guarani. Entretanto, quando se pergunta qual a língua que fala quando vai à escola, a informante responde que fala $\mathrm{PB}$. A reação da informante demonstra a possibilidade de que haja pouco contato linguístico com o PB na escola, pois frequenta o primeiro ano do Ensino Fundamental, o que denota uma insegurança linguística em relação ao domínio do PB.

$\mathrm{Na}$ resposta de $5 \mathrm{M} 3$, chamam a atenção duas ocorrências de "tudo", ao afirmar "tudo Guarani”" e "tudo igual". Isso indica a possibilidade de que na escola a totalidade dos falantes da aldeia utiliza o guarani. Ao afirmar "tem algum fala portugue?", associa o PB com professores e funcionários não indígenas, e quando diz "algum tem ingleis" refere-se à professora de inglês. Em relação à aprendizagem, 5M3 destaca que as crianças aprendem o guarani e o PB. A informante 6M3 não responde diretamente quais são as línguas faladas na escola, mas demonstra a percepção de que os professores ensinam guarani, PB e espanhol, ou seja, expõe a vivência de contato linguístico com três línguas no contexto escolar. 
Em relação à pergunta 22b, Como você se sente(ia) quando precisa(va) usar o português na escola?, as seis informantes manifestaram o componente afetivo, para afirmar que sentem ou sentiam vergonha ou timidez ao falar em PB e acionam os componentes cognoscitivo e conativo para explicar o pensamento e reação ao uso do PB na escola. Observem-se as respostas:

Pergunta 22b: Como você se sente(ia) quando precisa(va) usar o português na escola?

Inf. $1 \mathrm{M} 1$

L341INF: No tempo que eu estudava fora, eu me sentia mal até, assim, que eu tinha vergonha, assim, de falar em português e errar alguma palavra, e eu falava e parava, assim, não falava mais. Eu, quando eu errava a palavra en já ficava quieta, então hoje em dia, que nem eu falei, as crianças acho que não tem mais essas tantas dificuldades pra falar em português

Inf. 2M1

L120INQ: E como é que você se sente, quando você vai lá na APAE, tendo que falar o português?

L122INF: Bom, me sinto assim, estranho no meio dos outros ((risos)), não os indios né, mas eu me sinto segura lá, porque lá tem todos os especialistas, né. Ai lá tem assistência com psicólogo que conversa bastante com a gente, ai lá eu fui aprendendo mais a dialogar com os outros

Inf. $3 \mathrm{M} 2$

L178INQ: O que que é mais difícil?

L179INF: Ah, mais difícil prá completar ... assim, dá pra gente fazer ... prá completar a pergunta (em português) é mais difícil, a gente não sabe o que que vai fazer, e o professor explica tudo ai a gente acaba esquecendo, dai é mais difícil ainda pra fazer

Inf. $4 \mathrm{M} 2$

L187INF: Eu sentia ... queria falá ... eu sentia assim antes ... antes de escola ... queria aprendé falá, porque eu pensei um dia cumprir trabalbo, prá podé falá tudo em português

Inf. $5 \mathrm{M} 3$

L258INF: eu não consegui oiá muito ... falto oculo... fazế oculo e depois que ele continua 


\section{Inf. 6M3}

L801INF: é mai melhó falá a língua Guarani... não adianta a gente qué falá otra lingua prá mim parece que num vai dá certo não

Observa-se que 1M1 apresenta segurança linguística em relação ao PB e aciona três vezes o advérbio de modo "assim" para manifestar o componente afetivo de que se sentia "mal" e com "vergonha" na escola, porque tinha medo de errar alguma palavra, e sua reação era parar e não falava mais com os colegas ou a professora. Em seguida, 1M1 tem a percepção de que, atualmente, as crianças não têm mais essa dificuldade para falar em PB. Também nas respostas de 4M2 e 5M3 foi identificada essa dificuldade, tendo em vista que as informantes demonstraram maior timidez e pausas, ou seja, não conseguiram se expressar devido à falta de domínio do PB. As informantes 4M2 e 5M3 demonstraram, de certo modo, a mesma situação vivenciada por 1M1 quando não dominava o PB.

A informante 2M1 aciona o componente afetivo ao afirmar que se sente "estranho no meio dos outros", mas que atualmente está mais segura porque foi aprendendo a dialogar com os outros. Essa constatação de 2M1 aponta indícios do componente conativo. Já 3M2 afirma que é difícil falar em PB porque, apesar de o professor explicar, o aluno acaba esquecendo e não sabe o que vai fazer para responder à pergunta em $\mathrm{PB}$. O processo de aprendizagem do PB exige, por parte do aluno, um esforço ainda maior para compreensão do conteúdo escolar. Para 4M2, é melhor falar a língua guarani do que falar em outra língua; e revela o sentimento de que "parece que num vai dar certo não".

A manifestação da dificuldade de falar e o medo de errar também puderam ser identificados no comportamento de algumas informantes durante a realização das entrevistas. Essa dificuldade de comunicação pode estar relacionada ao nível de escolaridade das informantes, tendo em vista que as duas com escolaridade de Ensino Médio e Ensino Fundamental II completo demonstraram mais facilidade na oralidade em PB e menor grau de timidez durante a entrevista, em comparação com 3M2 e 5M3, respectivamente das faixas etárias 2 e 3, e com escolaridade no Ensino Fundamental I incompleto.

Em resposta à pergunta 44, apenas uma informante nomeou uma língua como feia, duas disseram que não existe uma língua feia, uma não soube responder e outra não respondeu porque "quer ter amizade com todo mundo". Vejam-se as respostas:

Pergunta 44: Qual é a língua mais feia? Por quê?

Inf. $1 \mathrm{M} 1$

L656INF: Lingua mais feia? Prá mim não existe uma não sei falar assim ... porque as linguas portuguesas, paraguaia ou espanbol, on lingua caingangue prá mim pode ser feio mas prá eles que entendem sempre 
também vai ser língua ... então não existe, prá mim não existe línguas pior nem melhor

Inf. $2 \mathrm{M} 1$

L323INF: Isso não sei dizer

L324INQ: Por quê?

L325INF: É porque eu não tenho, eu não acho que tenha uma lingua feia, é isso

Inf. $3 \mathrm{M} 2$

L486INF: mais feia não sei ((risos)) ... não sei

L487INQ: por que você não sabe?

L488INF: eu não posso falá que eu não entendo também as outras línguas ... eu não sei ... então eu não sei qual que é mais feia

Inf. 4M2

L451INF: Acho que espanbol ((risos))

L452INQ: Por quê?

L453INF: Porque eu não sei falá espanbol

Inf. $5 \mathrm{M} 3$

L477INQ: e qual a língua mais feia?

L478INF: ((silêncio)) eu tamem não acho prá ... eu tamem tudo igual

Inf. $6 \mathrm{M} 3$

L686INF: ((risos)) não quero fazer feio prá ninguém... quero ter amizade com todo mundo

Para a informante 1M1, "não existe linguas pior nem melhor", o que demonstra a consciência linguística da falante em relação às diferenças entre as línguas, ou seja, uma língua que é feia para ela pode não ser feia para outro falante. A informante 5M3 responde que não tem língua feia e, ao afirmar "eu tamém tudo igual", denota sua crença de que todas as línguas são iguais. As informantes 2M1 e 3M2 não souberam dizer qual é a língua mais feia, mas revelaram diferença de percepção, porque $2 \mathrm{M} 1$ afirma "eu não acho que tenha uma língua feia" e 3M2 diz "eu não posso falá que eu não entendo também as outras linguas". A informante 4M2 foi a única que nomeou uma língua como feia, o espanhol, e justificou sua escolha porque não fala espanhol, ou seja, avalia que as línguas guarani e PB têm mais prestígio porque é bilíngue. A informante $6 \mathrm{M} 3$ não respondeu à pergunta e sua reação foi uma risada seguida de pausa, o que indica uma reflexão sobre a questão e o controle de sua fala. Em seguida, 6M3 afirma "não quero fazer feio prá ninguém... quero ter 
amizade com todo mundo", o que denota que a língua está conectada com o entorno sociocultural da falante.

Resumindo, as respostas das informantes são manifestações de suas relações com os falantes do contexto sociocultural dentro e fora do Tekoha Añetete, em conformidade com o que aponta Moreno Fernández (2012, p. 49-50):

A influência do ambiente social é condicionada pela maneira como os falantes interpretam seus perfis linguísticos reciprocamente, assim como pela maneira como categorizam e percebem a organização social e sua dinâmica, inclusive a comunicativa. ${ }^{7}$

Portanto, o posicionamento do falante sobre a língua mais bonita e mais feia tem influência do ambiente sociocultural em que vivem e pela forma como o falante manifesta os elementos afetivo, cognoscitivo e conativo na sua relação com os agrupamentos sociais e seus membros.

A última resposta analisada se refere à pergunta 47, Se você precisasse trabalhar fora da aldeia, você procuraria um patrão brasileiro, um argentino ou um paraguaio? Quatro informantes disseram que procurariam um brasileiro, uma não escolheu e uma não soube responder. Observem-se as respostas:

Pergunta 47: Se você precisasse trabalhar fora da aldeia, você procuraria um patrão brasileiro, um argentino ou um paraguaio? Por quê?

Inf. $1 \mathrm{M} 1$

L742INQ: E se você precisasse trabalhar fora da aldeia, você procuraria um brasileiro, um argentino ou um paraguaio?

L744INF: Brasileiro

L745INQ: Por quê?

L746INF: Porque eu me entenderia melhor com a pessoa. Aqui eu conheço mais a pessoa, assim, e também, se eu fosse trabalhar fora eu pegaria trabalho só com a pessoa que eu confio, que en já conbeço, ou a pessoa que eu conbeço pode me indicar e dai en não pegaria trabalho em qualquer lugar

Inf. $2 \mathrm{M} 1$

L374INF: Pra mim seria melhor brasileiro

L375INQ: Por quê?

L376INF: Porque eu entendo melhor essa lingua

${ }^{7}$ La influencia del entorno social viene condicionada por la forma en que los hablantes interpretan reciprocamente sus perfiles lingüisticos, asi como por el modo como categorizan y perciben la organización social y su dinámica, incluida la comunicativa. 
Inf. 3M2

L550INF: Um brasileiro

L551INQ: Por quê?

L552INF: Porque tem que ir direto no hospital, dai tem que ser brasileiro

L553INQ: Então o brasileiro por quê? Por que é mais fácil?

L554INF: É, é mais fácil porque atende lá mesmo onde que trabalha, o pessoal daqui tem tudo lá, médico, enfermeira, dai lá dentro mesmo

Inf. $4 \mathrm{M} 2$

L500INF: Acho que brasileiro

L501INQ: Por quê?

L502INF: Porque consigo falar o português, preciso trabalhar e tenho que sair e conversar com as pessoas

Inf. $5 \mathrm{M} 3$

L586INF: Não

L587INQ: você não ia trabalhar fora da aldeia?

L588INF: não

Inf. $6 \mathrm{M} 3$

L785INQ: Num sei isso tamém... nunca trabaiei ... só trabaiei quando era minina ... trabaiei pro branca que falei prá sinhora

A informante 1M1 disse que trabalharia com brasileiro, mas ressaltou que "pegaria trabalbo só com a pessoa que eu confio, que eu já conheço, ou a pessoa que eu conbeço pode me indicar". Observa-se que a atitude da informante está condicionada a uma relação de confiança com uma pessoa que conhece ou indicação. A resposta de 3M2 também justifica seu posicionamento favorável ao brasileiro porque ela trabalha na área de saúde e tem facilidade de relacionamento, e justifica: "é mais fácil porque atende lá mesmo onde que trabalha (no posto ou hospitall". As informantes 2M1 e 4M2 disseram que procurariam um brasileiro porque entendem e falam o PB, conforme explicam: "entendo melhor essa lingua" (Inf. 2M1) e "consigo falar o português, preciso trabalhar e tenho que sair e conversar com as pessoas" (Inf. 4M2). As respostas das informantes 5M3 e 6M3 possivelmente estão atreladas ao fato de que as informantes têm pouco contato fora da aldeia, principalmente em relação ao trabalho. A maioria das informantes justificou a escolha do brasileiro devido ao domínio da fala em PB, relacionamento de confiança e facilidade do trabalho.

As respostas das informantes em relação às cinco perguntas analisadas neste artigo revelam que a situação linguística do guarani na fronteira do Brasil com o Paraguai e Argentina é complexa e que há diversidade linguística nesta região de contato das 
línguas indígenas com o PB e o espanhol. As informantes demonstraram que têm consciência das diferenças do guarani falado na aldeia, no Paraguai e na Argentina. Observou-se que o posicionamento manifestado pelas informantes está relacionado ao nível de conhecimento e à percepção de cada informante em relação à fala de outro.

\section{Considerações Finais}

Dos três componentes estudados, podemos observar que indícios linguísticos dos componentes afetivo e cognoscitivo são praticamente pautados em modalizadores e itens lexicais que representam o conhecimento e o sentimento da família e da aldeia.

Constatou-se que o componente cognoscitivo favorece que as informantes manifestem as percepções individuais de acordo com o perfil etnolinguístico e das práticas comunicativas que vivenciam dentro e fora da aldeia Tekoha Añetete. Já o componente afetivo revela o sentimento de valoração da língua materna guarani em contato com o $\mathrm{PB}$, e o componente conativo mostra o comportamento social do falante em relação à língua guarani e a outras línguas de contato.

Quando a informante está respondendo a uma pergunta, pauta-se em algo que está acontecendo naquele momento, que pode acontecer no futuro, ou narrar algumas atitudes que vivenciou no passado. Ela está agindo de acordo com a pergunta da inquiridora, o que gera um comportamento no indivíduo, no exato momento da entrevista. Nesse sentido, as percepções e a consciência dessas informantes incidem de forma indireta sobre suas atitudes e sobre suas condutas linguísticas.

Vale destacar que, segundo as teorias mentalistas, a atitude é um estado mental interno situado entre um estímulo e uma resposta a este estímulo. Por um lado, permite antecipar comportamentos, considerando que a pergunta está anterior a uma resposta. São manifestações internas que não podem ser observadas e analisadas de maneira direta, senão por meio de inferências e suposições a partir do comportamento e do testemunho dos falantes. São processos inconscientes sobre os quais geralmente os falantes não fazem reflexões explícitas, mas a pergunta movimenta uma conduta. Nesse sentido, as percepções e a consciência das informantes incidem de forma indireta sobre suas atitudes e sobre suas condutas linguísticas. É preciso considerar que a conduta do indígena seria conduzida pelas orientações da inquiridora branca durante a realização do inquérito para geração dos dados, além do olhar, gestos, manejos da mão, tom de voz etc.

É perceptível, nas respostas, a respeito da avaliação das línguas, que o guarani é a língua de prestígio. As informantes mulheres explicam que ensinam o PB para as crianças como algo necessário, principalmente para se defenderem no futuro - e isso diz respeito ao que a cultura do branco impõe. Constata-se que as pressões externas da sociedade e as pressões internas da comunidade constituem duas forças que atuam nas atitudes e usos linguísticos do guarani e PB na comunidade de fala. 
Nos inquéritos, fica clara a convivência com os falantes do PB e verifica-se a consciência da necessidade de aprender o português, mas também a expressa necessidade de reafirmar a valorização do guarani. O PB é visto como uma espécie de passaporte para o mundo do branco. As informantes mais jovens estudam PB para que possam ter acesso a um curso superior e a oportunidades de trabalho fora e dentro da aldeia - na escola, no posto de saúde e em outras funções, como em projetos de assistência técnica agropecuária e saneamento básico.

As conclusões deste estudo apontam para duas principais motivações que levam as informantes a aprenderem o PB. A primeira, em que a aprendizagem é motivada somente pelo caráter de utilidade da língua, considerada apenas um instrumento para que se alcancem objetivos, como estudar, trabalhar fora da aldeia, comprar produtos de consumo, receber proventos, entre outros. A segunda é motivada com a finalidade comunicativa, na qual o indivíduo pretende dominar a cultura dos falantes do PB e a integração não é tida como aculturação. Ou seja, a língua é aprendida somente porque ela é necessária, muitas vezes, para a própria sobrevivência do falante.

\section{REFERÊNCIAS}

ABREU, R. L. Parana MesoMicroMunicip.svg, own work. 2006. Disponível em: https://bit.ly/2WRQK4r. Acesso em: 10 out. 2018.

AGUILERA, V. A. Crenças e atitudes lingüísticas: o que dizem os falantes das capitais brasileiras. Estudos Lingüísticos, São Paulo, v. 37, n. 2, p. 105-112, maio/ago. 2008.

AGUILERA, V. A. Crenças e atitudes linguísticas: um estudo da relação do português com línguas de contato. 2009. (Projeto). (Cópia da autora).

AGUILERA, V. A; SILVA, H. C. O poder de uma diferença, um estudo sobre crenças e atitudes linguísticas. Alfa, São Paulo, v. 58, n. 3, p. 703-723, 2014.

BLANCO CANALES, A. Estudio sociolingüistico de Alcalá de Henares. Alcalá de Henares, Madrid: Servicio de Publicaciones de la Universidad de Alcalá, 2004.

BORTOLINI, J. C. O sujeito guarani: o discurso da sustentabilidade nas comunidades indígenas (2003/2013). 2014. Dissertação (Mestrado em Letras) - Universidade do Oeste do Paraná, Cascavel, 2014.

CARVALHO, M. L. B. Das terras dos indios a indios sem terras. O Estado e os Guarani do Oco'y: violência, silêncio e luta. 2013. Tese (Doutorado em Geografia Humana) Universidade de São Paulo, São Paulo, 2013. 
CONSELHO NACIONAL DE SAÚDE. Resolução Nº 466, 12 de dezembro de 2012. Disponível em: https://bit.ly/3fQ9aLQCNS466. Acesso em: 24 jun. 2015.

CONSELHO NACIONAL DE SAÚDE. Resolução Nº 510, de 7 de abril de 2016. Disponível em: https://bit.ly/3bus5rVCNS510. Acesso em: 15 mai. 2016.

CORBARI, C. C. Atitudes linguísticas: um estudo nas localidades paranaenses de Irati e Santo Antônio do Sudoeste. 2013. Tese (Doutorado em Letras e Linguística) Universidade Federal da Bahia, Salvador, 2013.

D’ANGELIS, W. Guarani. Campinas: Laboratório de Estudos Linguísticos. Portal Labeurb. Disponível em: https://bit.ly/3dHIXhGguarani. Acesso em: 10 out. 2015.

FISHMAN, J. A. Sociolinguistics. In: FISHMAN, J. A. (Ed.). Handbook of language and ethnic identity. New York: Oxford University Press, 1999. p. 152-163.

FUNAI. Instrução Normativa $N^{0}$ 001/PRES, de 29/NOVEMBRO/1995. Disponível em: https://bit.ly/2T69yfoIN1995. Acesso em: 20 abr. 2015.

FUNAI. Ingresso em terra indígena. Disponível em: https://bit.ly/2WuIiJnITInd. Acesso em: 20 abr. 2015.

FUNAI. Índios no Brasil - Terras Indígenas. Disponível em: https://bit.ly/2yJcKXr. Acesso em: 16 jul. 2018.

GÓMEZ MOLINA, J. R. Actitudes lingüísticas en Valencia y su área metropolitana: evaluación de cuatro variedades dialectales. In: CONGRESO INTERNACIONAL DE LA ASOCIACIÓN DE LINGÜÍSTICA Y FILOLOGÍA DE LA AMÉRICA LATINA - ALFAL, 11., 1996, Las Palmas de Gran Canaria. Actas... Las Palmas de Gran Canaria: Universidad de Las Palmas de Gran Canaria, 1996. v. 2. p. 1027-1042.

IBGE. Censo Demográfico 2010 - Terras Indígenas. Disponível em: https://bit.ly/ 2YXtlRVterrind. Acesso em: 26 jul. 2016.

IBGE. Censo Demográfico 2010 - Panorama. Disponível em: https://bit.ly/2SXtm4f. Acesso em: 25 ago. 2019.

IBGE. Diamante d'Oeste. Brasil/Paraná. História \& Fotos. Disponível em: https:// bit.ly/35WZaeR. Acesso em: 25 ago. 2019.

LABOV, W. Padrões sociolinguísticos. Tradução de Marcos Bagno, Maria Marta Pereira Scherre e Caroline Rodrigues de Oliveira. São Paulo: Parábola, 2008 [1972].

LAMBERT, W. W.; LAMBERT, W. E. Psicologia social. 3. ed. Rio de Janeiro: Zahar, 1966. 
MELIÀ, B. Pasado, presente y futuro en la lengua guaraní. Asunción: CEADUC, 2010.

MENDONÇA, S. C. P. Crenças e atitudes linguisticas: estudo na aldeia Guarani Tekoba Añetete em Diamante d'Oeste/PR. 2019. Tese (Doutorado em Letras) - Universidade Estadual do Oeste do Paraná, Cascavel, 2020.

MORENO FERNÁNDEZ, F. Principios de sociolingüistica y sociologia del lenguaje. Barcelona: Ariel, 1998.

MORENO FERNÁNDEZ, F. Sociolingüistica Cognitiva: proposiciones, escolios y debates. Madrid: Iberoamericana, 2012.

VON BORSTEL, C. A linguagem sociocultural do Brasildeutsch. São Carlos: Pedro \& João, 2011. 